\title{
Paul Stewart, Zone of Evaporation. Samuel Beckett's Disjunctions
}

\section{Emanuele Kanceff}

\section{Q OpenEdition \\ 1 Journals}

\section{Edizione digitale}

URL: https://journals.openedition.org/studifrancesi/26846

DOI: 10.4000/studifrancesi.26846

ISSN: 2421-5856

\section{Editore}

Rosenberg \& Sellier

\section{Edizione cartacea}

Data di pubblicazione: 1 avril 2007

Paginazione: 215

ISSN: 0039-2944

\section{Notizia bibliografica digitale}

Emanuele Kanceff, «Paul Stewart, Zone of Evaporation. Samuel Beckett's Disjunctions», Studi Francesi [Online], 151 (LI | I) | 2007, online dal 30 novembre 2015, consultato il 23 novembre 2021. URL: http:// journals.openedition.org/studifrancesi/26846 ; DOI: https://doi.org/10.4000/studifrancesi.26846

Questo documento è stato generato automaticamente il 23 novembre 2021.

\section{(c) (i) (9)}

Studi Francesi è distribuita con Licenza Creative Commons Attribuzione - Non commerciale - Non opere derivate 4.0 Internazionale. 


\title{
Paul Stewart, Zone of Evaporation. Samuel Beckett's Disjunctions
}

\author{
Emanuele Kanceff
}

\section{NOTIZIA}

PAUL STEWART, Zone of Evaporation. Samuel Beckett's Disjunctions, Amsterdam, Rodopi, 2006, pp. 211 (Coll. "Faux Titre", 287).

1 Un volume molto accurato, che non vuole essere un generico discorso su Beckett, ma si rivolge alla sua narrativa, immediatamente riconoscibile a causa delle sue prerogative, così come Beckett rimane Beckett in tutte le sue espressioni, sia che si tratti di teatro o di prosa o di creazione radiofonica.

2 In questo studio i due grandi riferimenti del confronto sono Proust e Derrida. Appunto con la visione proustiana e il sogno beckettiano si apre il discorso, che si focalizza sulle differenze della memoria, sulla metafora e sulla dissimile messa in opera del ricordo involontario, sulla dissimile concezione delle relazioni umane e dell'esistenza, sulle divergenze di ordine narrativo.

3 L'autore studia poi Watt e la commedia della disgiunzione narrativa che si riflette in disgiunzione grammaticale; la narratologia in Molloy; l'«Unnamable», per approdare al punto focale del confronto con Derrida, e alla centralità dei Three Dialogues with Georges Duthuit, "porta regale di entrata nell'opera beckettiana", senza dimenticare di tener d'occhio il naturale istinto comico di Beckett. 